\title{
Comparative evaluation of low dose-vaginal misoprostol and intra- cervical dinoprostone for cervical ripening and induction of labour in term pregnancy
}

\author{
Priyanka Sharma*, Sujata Sharma, Harbhajan Kaur Shergill
}

Department of Obstetrics and Gynaecology, Government Medical College, Amritsar, Punjab, India

Received: 23 September 2016

Accepted: 20 October 2016

\author{
*Correspondence: \\ Dr. Priyanka Sharma, \\ E-mail: priyanka_labelle@yahoo.co.in
}

Copyright: (c) the author(s), publisher and licensee Medip Academy. This is an open-access article distributed under the terms of the Creative Commons Attribution Non-Commercial License, which permits unrestricted non-commercial use, distribution, and reproduction in any medium, provided the original work is properly cited.

\begin{abstract}
Background: Induction of labour is one of the most common obstetric interventions worldwide. The study was conducted to compare the efficacy and safety of $25 \mu \mathrm{g}$ (low dose) vaginal Misoprostol with intracervical Dinoprostone for cervical ripening and induction of labour in term pregnancy.

Methods: The study was conducted on 200 eligible term gravidas admitted for the purpose of labour induction.

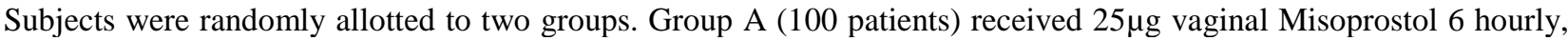
while Group B (100 patients) received intracervical Dinoprostone 6 hourly for a maximum of 3 doses each, for cervical ripening and induction of labour. The main outcomes analysed were the induction-to-vaginal delivery interval, number of vaginal deliveries within 24 hours, dose of prostaglandin required, need for oxytocin augmentation and incidence of operative or caesarean delivery and rates of hyper stimulation, maternal complications and neonatal outcome.

Results: Misoprostol use was associated with shorter induction-to-vaginal delivery interval (1165.60+306.28 minutes $\mathrm{v} / \mathrm{s} 1369.80+286.96$ minutes, $\mathrm{p}=<0.001)$, a greater proportion of patients delivering vaginally within 24 hours $(67 \%$ $\mathrm{v} / \mathrm{s} 46 \%, \mathrm{p}=0.001)$ and lesser need for oxytocin augmentation to achieve vaginal delivery $(25.3 \% \mathrm{v} / \mathrm{s} 54.7 \%$, $\mathrm{p}<0.001)$.The mean change in Bishop's score was greater with Misoprostol, although the difference was not statistically significant. The rates of operative and caesarean deliveries, and indications for caesarean were similar in both groups. The rates of uterine hyper stimulation, maternal and neonatal outcomes were similar.

Conclusions: Vaginal Misoprostol is more efficacious than intracervical Dinoprostone for induction of labour in term gravidas.
\end{abstract}

Keywords: Cervical ripening, Dinoprostone, Labour induction, Low- dose misoprostol

\section{INTRODUCTION}

Induction of labour is the intentional initiation of labour for the purpose of delivery of the fetoplacental unit. It is carried out in $20 \%$ deliveries. ${ }^{1}$ Oxytocin and prostaglandins are the main stay for labour induction. Cervical favorability is the prime determinant of success of labour induction and vaginal delivery. The incidence of failed induction in unripe cervices is up to $50 \%$. $^{2}$
Oxytocin does not promote cervical ripening. Prostaglandins, on the other hand, stimulate myometrial contractions as well as facilitate cervical ripening. Two prostaglandin analogues are available commercially. Dinoprostone $\left(\mathrm{PGE}_{2}\right)$ gel is a licensed, time tested preparation and is recommended widely as the preferred agent for labour induction. Misoprostol is a $\mathrm{PGE}_{1}$ analogue used through oral or vaginal route. It is used widely off label as an abortifacient and for labour induction. As compared to Dinoprostone, Misoprostol has 
certain decided advantages. It is stable at room temperature, does not require special storage, is inexpensive, less invasive to use, has no bronchoconstrictor action and can be administered through several routes. There has been concern about uterine hyper stimulation with the use of higher doses of Misoprostol. Recent published studies have, however, established that lower dosages of Misoprostol give similar or better results than $\mathrm{PGE}_{2}$, but with similar safety profile. ${ }^{3-5}$ The $25 \mu \mathrm{g}$ dose is as effective as the $50 \mu \mathrm{g}$ dose and with reduced risk of hyperstimulation. ${ }^{6}$

This study aims to compare the efficacy and safety of low dose $(25 \mu \mathrm{g})$ vaginal Misoprostol with intracervical Dinoprostone for cervical ripening and induction of labour in term pregnancies.

\section{METHODS}

This was a retrospective study conducted from Jan 2011 The present study on the "Comparative Evaluation of Low dose- Vaginal Misoprostol and Intracervical Dinoprostone for Cervical Ripening and Induction of Labour in Term Pregnancy" was conducted on 200 term gravidas admitted in the antenatal ward/labour room of Department of Obstetrics and Gynaecology, Shri Guru Tegh Bahadur Hospital/ Bebe Nanke Centre for Mother and Child Care, Government Medical College, Amritsar. After approval from the Hospital Ethics Committee, informed consents were obtained from each participant. Allocation to the two study groups was carried out through computer generated randomisation sequence sealed in an opaque envelope.

All term gravidas $>18$ years old, with accurately dated single viable cephalic gestation, a Bishop's score of $\leq 5$ and a reactive non stress test prior to induction were included in the study.

Grand multiparas, women with history of prior uterine surgery, any suspicious vaginal bleeding, multiple pregnancies, suspected cephalopelvic disproportion, non vertex presentation, abnormal placentation and history to cardiac disease, glaucoma, asthma, or drug allergy were excluded from the study.

A detailed history was taken and a comprehensive general physical, systemic and obstetric examination was carried out.

After the assessment of the cervical Bishop's score following a reactive NST, patients were allocated to two groups. Patients in group A were administered $0.5 \mathrm{mg}$ Dinoprostone gel (Cerviprime Gel 0.5mg, Astra Zeneca) intracervically and those in group B were administered 25 $\mu \mathrm{g}$ Misoprostol tablet (Tab Misoprost 25 $\mu \mathrm{g}$, Cipla) per vaginum.

In both groups, the blood pressure, pulse rate, uterine activity and foetal heart rate were monitored and noted every 15 minutes for the first hour and half hourly thereafter. The onset of uterine contractions, duration, frequency and intensity of contractions were noted and patient was monitored for uterine tachysystole, hyper tonus, hyper stimulation or non-reassuring foetal heart rate patterns.

If and when the patient went into active labour, liquor was meconium stained or the FHR was not reassuring, the patient was transferred to the labour room and further prostaglandin doses were withheld. After the administration of the first dose, the patient vitals, fetal heart rate and onset of uterine contractions were monitored. If at $6 \mathrm{hrs}$, good uterine contractions (2 or more lasting $25-30$ seconds each in a 10 minute period) were established and Bishop's Score $>5$, further doses were withheld and, augmentation, if and when required was carried out with oxytocin infusion and amniotomy. If there were no adequate pains or for Bishop's Score $\leq 5$, doses were repeated at 6,12 and $18 \mathrm{hrs}$. Successful induction was defined as the occurrence of vaginal delivery within $24 \mathrm{hrs}$. In the event of uterine hyper stimulation, the patient was put in left lateral position, intranasal oxygen inhalation was given and intravenous Dextrose Normal Saline drip was started. Tocolytics were administered for reversal of hyper stimulation. The trial was interrupted and decision for operative intervention taken, if the aforementioned measures failed. Caesarean section was performed for failure to progress and fetal distress.

For the purpose of the trial, foetal distress was defined as persistent or recurring episodes of severe variable or late decelerations, late decelerations, or prolonged foetal bradycardia, or a combination of decreased beat-to-beat variability and a decelarative pattern with or without the presence of meconium stained liquor. Non progress of labour was defined as no change in cervical dilatation during the active phase of labour for two consecutive hours or no progress in the descent of the foetus through the birth canal in the second stage of labour for 1 hour in the presence of adequate uterine contractions.

The primary outcome measures studied were the number of vaginal deliveries occurring within 24 hours and the induction- to- vaginal delivery interval. The secondary outcome measures were the number of prostaglandin doses required, need for oxytocin augmentation, duration of labour, maternal hyper stimulation and foetal outcome as described by need for resuscitation in the labour room, APGAR scores at 1 and 5 minutes and admission to the NICU.

\section{Statistical analysis}

Statistical analysis was performed on the SPSS Version 20. Continuous data was reported as mean \pm SD. Analysis of continuous data was accomplished by means of a two tailed Student- $t$ test. The $\chi^{2}$ test or Fischer's exact test was used to compare the non parametric data. 


\section{RESULTS}

The patients in both groups were similar with respect to age, gestational age, parity, pre induction cervical score and indication for induction (Table 1). No patients were excluded from analysis. No patients were lost to follow up.

Table 1: Clinical characteristic of study groups.

\begin{tabular}{|c|c|c|c|}
\hline Clinical characteristic & Misoprostol $(\mathbf{N}=100)$ & Dinoprostone $(\mathrm{N}=\mathbf{1 0 0})$ & $P$ value \\
\hline Mean patient age (in years) & $24.12 \pm 3.47$ & $23.54 \pm 2.95$ & 0.157 \\
\hline Mean gestational age (in days) & $273.41 \pm 9.55$ & $273.45 \pm 9.88$ & 0.361 \\
\hline Parity - Nullipara & $50(50 \%)$ & $55(55 \%)$ & \multirow{2}{*}{0.861} \\
\hline Multipara & $50(50 \%)$ & $45(45 \%)$ & \\
\hline Mean pre induction Bishops score & $1.83 \pm 1.27$ & $1.76 \pm 1.33$ & 0.848 \\
\hline Indication for induction & & & \multirow{5}{*}{0.479} \\
\hline Post dated pregnancy & $25(25 \%)$ & $29(29 \%)$ & \\
\hline $\mathrm{PIH}$ & $28(28 \%)$ & $26(26 \%)$ & \\
\hline PROM & $23(23 \%)$ & $25(25 \%)$ & \\
\hline Others & $24(24 \%)$ & $20(20 \%)$ & \\
\hline
\end{tabular}

Table 2: Labour outcome in study groups.

\begin{tabular}{|c|c|c|c|}
\hline & Misoprostol & Dinoprostone & P value \\
\hline Modes of delivery & $\mathrm{N}=100$ & $\mathrm{~N}=100$ & 0.979 \\
\hline Normal Vaginal Delivery & $85(85 \%)$ & $84(84 \%)$ & \\
\hline Caesarean Delivery & $13(13 \%)$ & $14(14 \%)$ & \\
\hline Operative Vaginal Delivery & $2(2 \%)$ & $2(2 \%)$ & \\
\hline Induction to vaginal delivery interval & $\mathrm{N}=87$ & $\mathrm{~N}=86$ & 0.002 \\
\hline$<12$ hours & $8(9.2 \%)$ & $2(2.3 \%)$ & \\
\hline 12-24 hours & $59(67.8 \%)$ & $44(51.2 \%)$ & \\
\hline$>24$ hours & $20(23 \%)$ & $40(46.5 \%)$ & \\
\hline Induction- to- active labour interval (in minutes) & $464.35 \pm 253.61$ & $617.57 \pm 242.72$ & $<0.001$ \\
\hline Induction - to- vaginal delivery interval (in minutes) & $1165.60 \pm 306.28$ & $1369.80 \pm 286.37$ & $<0.001$ \\
\hline \multicolumn{3}{|l|}{ Mean change in Bishops score } & \multirow{4}{*}{$<0.001$} \\
\hline At 6 hours & $1.81 \pm 1.57$ & $1.29 \pm 1.61$ & \\
\hline At 12 hours & $4.64 \pm 2.25$ & $3.75 \pm 2.68$ & \\
\hline At 18 hours & $7.25 \pm 2.52$ & $6.00 \pm 2.34$ & \\
\hline Oxytocin augmentation & $\mathrm{N}=87$ & $\mathrm{~N}=86$ & \multirow{3}{*}{$<0.001$} \\
\hline Yes & $22(25.3 \%)$ & $47(54.7 \%)$ & \\
\hline No & $65(74.7 \%)$ & $39(45.3 \%)$ & \\
\hline Uterine Hyperstimulation & $\mathrm{N}=100$ & $\mathrm{~N}=100$ & 0.733 \\
\hline None & $87(87 \%)$ & $86(86 \%)$ & \\
\hline Hypertonus & $4(4 \%)$ & $2(2 \%)$ & \\
\hline Tachysystole & $3(3 \%)$ & $6(6 \%)$ & \\
\hline Hyper stimulation syndrome & $6(6 \%)$ & $6(6 \%)$ & \\
\hline Indication for Caesarean section & $\mathrm{N}=13$ & $\mathrm{~N}=14$ & 0.333 \\
\hline Foetal distress & $8(61.5 \%)$ & $11(78.6 \%)$ & \\
\hline Failure to progress & $5(38.5 \%)$ & $3(21.5 \%)$ & \\
\hline
\end{tabular}

The number of patients achieving vaginal delivery was similar in the two groups. However, the number of patients achieving vaginal delivery within 24 hours was significantly more in the Misoprostol group $(77 \% \mathrm{v} / \mathrm{s}$ $53.3 \%)(\mathrm{p}=0.002)$. Of those delivering within 12 hours, $80 \%$ belonged to the Misoprostol group. The induction to vaginal delivery interval was significantly shorter in the Misoprostol group as compared to the Dinoprostone group. $(\mathrm{p}=0.002)$. The interval from induction of labour to onset of active labour was shorter in the Misoprostol group as compared to the Dinoprostone group (464.35 \pm 253.61 minutes v/s $617.57 \pm 242.72$ minutes, $\mathrm{p}<0.001)$ The mean duration of labour was significantly shorter in the Misoprostol group as compared to the Dinoprostone group (1165.60 \pm 306.28 minutes v/s $1369.80 \pm 286.37$ minutes, $\mathrm{p}<0.001$ (Table 2). 
More patients were induced successfully after only one dose of Misoprostol than Dinoprostone (27\% v/s 16\%). On the other hand, more patients required three doses to achieve induction in the Dinoprostone group. (19.4\% v/s $15.2 \%)$ The difference was, however, not statistically significant $(p=0.143)$. The mean number of doses required for successful induction in the Misoprostol group is $1.86 \pm 0.65$ and in the Dinoprostone group was $2.02 \pm 0.60$. The mean change in Bishop's score at 6,12 and 18 hours was significantly greater in the Misoprostol group (Table 2).

The need for augmentation with oxytocin was significantly greater in the Dinoprostone group as compared to the Misoprostol group ( $p<0.001)$. The incidence of hyper tonus, tachysystole and hyper stimulation were similar in the two groups (16\% v/s 14\%) $(\mathrm{p}=0.733)$ (Table 2). The commonly encountered side effects were nausea, vomiting, diarrhoea and pyrexia which were comparable in the two groups $(p=0.105)$. There were no uterine ruptures in either group. The main indications for Caesarean section in both groups were fetal distress and non progress of labour, and were comparable in both groups $(\mathrm{p}=0.333)$.

Majority of neonates (78\% in either treatment group) did not have any perinatal complications. The rate of meconium stained liquor was higher in the Misoprostol group as compared to the Dinoprostone group. The rates of other neonatal complications were similar in the two groups $(\mathrm{p}=0.244)$ (Table 3$)$. There were no intra uterine deaths or early neonatal deaths in either group.

Table 3: Neonatal Outcome in study groups.

\begin{tabular}{|llll|}
\hline $\begin{array}{l}\text { Neonatal } \\
\text { outcome }\end{array}$ & $\begin{array}{l}\text { Misoprostol } \\
(\mathrm{N}=100)\end{array}$ & $\begin{array}{l}\text { Dinoprostone } \\
(\mathrm{N}=100)\end{array}$ & $\begin{array}{l}\mathrm{P} \\
\text { value }\end{array}$ \\
\hline $\begin{array}{l}\text { Mean Birth } \\
\text { weight (in kg) }\end{array}$ & $2.98 \pm 0.42$ & $2.94 \pm 0.39$ & 0.593 \\
\hline $\begin{array}{l}1 \mathrm{~min} \\
\text { APGAR } \\
\text { Score }<7\end{array}$ & $9(9 \%)$ & $5(5 \%)$ & 0.268 \\
\hline $\begin{array}{l}5 \text { min } \\
\text { APGAR }\end{array}$ & $3(3 \%)$ & $2(2 \%)$ & 0.651 \\
\hline Score $<7$ & $8(8 \%)$ & $13(13 \%)$ & 0.249 \\
\hline $\begin{array}{l}\text { Need for } \\
\text { resuscitation }\end{array}$ & $9(9 \%)$ & $6(6 \%)$ & 0.421 \\
\hline $\begin{array}{l}\text { NICU } \\
\text { admissions }\end{array}$ & & \\
\hline
\end{tabular}

\section{DISCUSSION}

The present study has used the $25 \mu \mathrm{g} 6$ hourly dose for induction with vaginal Misoprostol in keeping with the latest WHO and ACOG recommendations., ${ }^{7,8}$ The regimen used for Dinoprostone has also been recommended by the ACOG in its guidelines on labour induction. ${ }^{8}$ The trial design and dosing regimens used have been in keeping with previous similar comparative studies by Blanchette et al, Shivarudraiah et al and Sheela $\mathrm{CN}$ et al. ${ }^{9-11}$ Our results demonstrate the superiority of low dose $(25 \mu \mathrm{g})$ vaginal Misoprostol over the time tested and standardised regimen involving Dinoprostone for cervical ripening and labour induction in term pregnancies. The induction to vaginal delivery interval has been most frequently employed to determine the success of induction regimens. Our study shows the Misoprostol achieves a significantly shorter induction to delivery interval, with lesser need for oxytocin augmentation and similar maternal and neonatal outcome as compared to intracervical Dinoprostone. The rates of Caesarean sections and indications for the same are also similar. The incidence of uterine hyperstimulation and consequent catastrophic maternal and foetal outcomes has been a major deterrent to its use in labour induction. Our study results show that the rates of hyper stimulation and foetal distress are comparable to those seen with Dinoprostone.

Sheela $\mathrm{CN}$ et al observed similar results in their comparison of $25 \mu \mathrm{g}$ Misoprostol with Dinoprostone gel vis-a-vis shorter induction to delivery intervals, greater proportion of women delivering within 24 hours and lesser need for oxytocin augmentation. ${ }^{11}$ A study conducted by Ramsey et al assessed $50 \mu \mathrm{g}$ vaginal Misoprostol against Dinoprostone gel and insert and concluded that Misoprostol was associated with a greater mean Bishops score change, shorter induction- todelivery interval and similar maternal and neonatal outcomes. $^{12}$ David Buser et al defined successful induction as the onset of good uterine contractions and a Bishops score $>5 .^{13}$ By this parameter, too, Misoprostol was associated with more successful inductions. As with previously mentioned authors, Buser et al also reported more vaginal deliveries within 24 hours and a lesser need for oxytocin augmentation with Misoprostol use.

A Cochrane review has noted a higher rate of uterine stimulation with Misoprostol but no increase in maternal morbidity, foetal adverse outcome or Caesarean birth rates. It has further stated that hyper stimulation is likely a dose dependent phenomenon, and in studies using 25 $\mu \mathrm{g}$ Misoprostol, hyper stimulation rates are similar to those induced with Dinoprostone. ${ }^{14}$ There was no uterine rupture in our study. Blanchette et al have reported four uterine ruptures in their study. However, it is of note that patients with previous caesarean sections were included in their study. ${ }^{9} 3$ of 4 ruptures occurred in scarred uteri whereas a one posterior rupture occurred in a case of shoulder dystocia. In our study, the risk of meconium stained liquor was greater in the Misoprostol group. However, the overall neonatal outcome was similar with both drugs.

The WHO included $25 \mu \mathrm{g}$ Misoprostol in its essential drugs list in 2007. ${ }^{15}$ In its 2011 recommendations for labour induction, it has proposed the use of $25 \mu \mathrm{g}$ vaginal Misoprostol for induction of labour in an unscarred 
uterus, thus lending further credibility to Misoprostol's claim as an efficacious and safe labour induction agent. ${ }^{7}$

\section{CONCLUSION}

Low dose vaginal Misoprostol is a more efficacious agent for labour induction and cervical ripening than intracervical Dinoprostone, but with an identical safety profile. Its use is less cumbersome and more cost effective. It has, therefore, an immense potential for application in labour induction especially in the developing world and resource poor settings.

Funding: No funding sources Conflict of interest: None declared

Ethical approval: The study was approved by the Institutional Ethics Committee

\section{REFERENCES}

1. Society of Obstetricians and Gynaecologists of Canada. Clinical practice guidelines. Induction of labour at term. No. 107, Ottawa: SOGC, 2001.

2. RCOG. Induction of labour. In Evidence-based Clinical Guideline Number 9. London: RCOG Clinical Support Unit, 2001.

3. Abdel-Aleem H. Misoprostol for cervical ripening and induction of labour: RHL commentary. WHO Reproductive Health Library; Geneva: World Health Organization, 2011.

4. NICE clinical guideline 70. Induction of Labour. London: National Institute of Health and Clinical Excellence, 2008.

5. Cunnigham FG, Gant FG, Leveno KJ, Gillstrap LC, Hauth JC, Wenstrom KD. Williams obstetrics. 21st edition: New York: Mc Graw- Hill Companies Inc; 2001.

6. Fuchs A, Fuchs F. Endocrinology of human parturition: a review. $\mathrm{Br} \mathrm{J}$ Obstet Gynecol. 1984;9:948-67.

7. World Health Organization. WHO recommendations for induction of labour. Geneva: World Health Organization, 2011.
8. American College of Obstetricians and Gynecologists. Induction of labour. Practice Bulletin No 107. Washington: American College of Obstetricians and Gynecologists; 2009.

9. Blanchette HA, Nayak S, Erasmus S. Comparison of the safety and efficacy of intravaginal Misoprostol (prostaglandin E1) with those of Dinoprostone (prostaglandin E2) for cervical ripening and induction of labour in a community hospital. Am J Obstet Gynecol. 1999;180(6):1551-6.

10. Shivarudraiah G, Palaksha MA. A randomized trial comparing low dose vaginal Misoprostol and Dinoprostone gel for labour induction. J Obstet Gynecol India 2011;61(2):153-60.

11. Sheela CN, Mhaskar A, George S. Comparison of vaginal Misoprostol and oral Misoprostol with intracervical Dinoprostone gel for labour induction at term. J Obstet Gynecol India. 2007;57(4):327-30.

12. Ramsey PS, Harris DY, Ogburn PL, Heise RH, Magtibay PM, Ramin KD. Comparative efficacy and cost of the prostaglandin analogs Dinoprostone and Misoprostol as labour pre induction agents. Am J Obstet Gynecol. 2003;188(2):560-5.

13. Buser D, Mora G, Arias F. A randomised comparison between Misoprostol and Dinoprostone for cervical ripening and labour induction in patients with unfavourable cervices. Obstet Gynecol. 1997;89(4):581-5.

14. Hofmeyr GJ, Gülmezoglu AM, Pileggi C. Vaginal Misoprostol for cervical ripening and induction of labour (Review). The Cochrane Library. 2010;(10):CD000941.

15. WHO Model List of Essential Medicines: 15th list, March 2007. Geneva: World Health Organization; $2007 . \quad$ http://www.who.int/ medicines/publications/essentialmedicines/en.

Cite this article as: Sharma $\mathrm{P}$, Sharma S, Shergill HK. Comparative evaluation of low dose-vaginal misoprostol and intra-cervical dinoprostone for cervical ripening and induction of labour in term pregnancy. Int J Reprod Contracept Obstet Gynecol 2016;5:4303-7. 